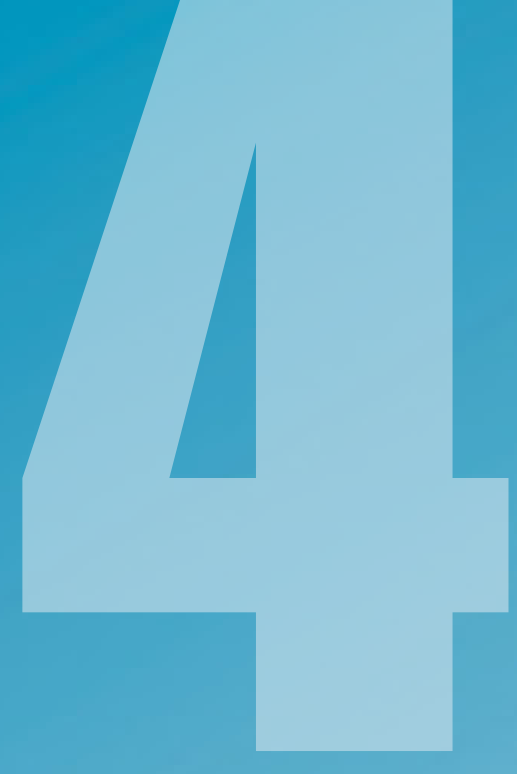

ÁMBITOS

REVISTA

INTERNACIONAL

DE COMUNICACIÓN

$N^{\circ} 46$

EDICIÓN OTOÑO

2019

ISSN: 1139-1979

E-ISSN: 1988-5733

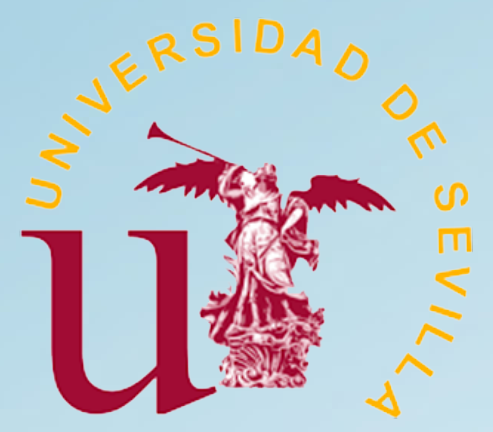




\section{ÍNDICE}

MONOGRAFICOS MONOGRAPHS

Presentación Monográfico. Comunicación emergente. Experiencias para el cambio social

Dra. Nereida López Vidales

Los formatos de televisión más consumidos por los jóvenes: telerrealidad y empoderamiento de la audiencia

Most consumed televisión formats by young people: real TV and the empowerment of the audience Nereida López Vidales, Leire Gómez Rubio, Elena Medina de la Viña

Nuevas herramientas, viejas costumbres El Contenido Generado por los Usuarios sobre el cambio climático en YouTube

New tools, old habits User Generated Content about climate change on YouTube

David Vicente Torrico

Tratamiento periodístico de personas LGTBIQ+ refugiadas: estudio de caso sobre Pride Barcelona 2018

Journalistic treatment of LGTBIQ+ refugees: case study on Pride Barcelona 2018

Hadriel Theodoro, Amparo Huertas Bailén

Tiempo Muerto, estudio de caso de un proyecto transmediático para la consecución de competencias universitarias

Tiempo Muerto, case study of a transmediatic project for the achievement of university competences Jose L. Carreño Villada, Miguel Ángel Díaz Monsalvo

Los universitarios millennials: uso de redes sociales y relación con las marcas

University Millennials: use of social media and engage with brands

Pedro Pablo Marín Dueñas, Esther Simancas González

Ali Ferzat: De la caricatura comunicativa en papel a la caricatura activista en los medios digitales

Ali Ferzat: From political cartoons in papers to political cartoons in digital media

Salud Adelaida Flores Borjabad

Direito à informação e literacia midiática: Reflexões sobre a questão do acesso

Right to information and media literacy: Reflections on the question of acce

Christiane Delmondes Versuti 
Eficacia de los influencers como recurso publicitario en la estrategia de los anunciantes locales Efficacy of influencers as an advertising resource in the strategy of local advertisers

Isabel Iniesta-Alemán

As redes sociais como ferramenta de marketing em instituições de ensino superior no Brasil Social networks as a marketing tool in higher education institutions in Brazil

Alcino Ricoy JR, Rogério Eduardo Rodrigues Bazi

Estudio sobre la conceptualización y el tratamiento informativo de la violencia de género en la prensa digital cubana

Study about the conceptualization and information treatment of gender violence in the Cuban digital press

Regla Ismaray Cabreja Piedra, Karina Escalona Peña

\section{ARTÍCULOS ARTICLES}

Uso de Twitter durante los debates electorales televisados en los comicios andaluces de 2018 The use of Twitter during the televised electoral debates in the 2018 Andalusian elections Julia Fontenla Pedreira, Erika Conde Vázquez, Carmen Máiz Bar

Quem averigua as notícias, os algoritmos ou jornalistas? A lógica crítica de C. S.

Peirce como processo de identificação de uma Fake News

Who checks the news, algorithms or journalists? The critical logic of C. S. Peirce as a

process for identifying a Fake News

Adelino de Castro Oliveira Simões Gala, Vania Baldi, Universidad de Aveiro

\section{RESEÑAS REVIEWS}

Nuevo ecosistema comunicativo digital: El consumidor

Juan Carlos Figuereo Benítez

Corpus toponímic de Beniarrés

Bianca Sánchez-Gutiérrez

The Future Computed. La inteligencia artificial y su papel en la sociedad y Pulsa actualizar. La aventura de redescubrir el alma de Microsoft y concebir un futuro mejor para todos 


\title{
Los formatos de televisión más consumidos por los jóvenes: telerrealidad y empoderamiento de la audiencia
}

\author{
Most consumed televisión formats by young people: real TV and \\ the empowerment of the audience
}

\author{
Nereida López Vidales, Universidad de Valladolid, Plaza del Campus \\ Universitario, s/n, 47011 Valladolid \\ nereida.lopez@hmca.uva.es | Orcid: http://orcid.org/0000-0002-6960-6129 \\ Leire Gómez Rubio, Universidad de Valladolid, Plaza del Campus Universitario, \\ s/n, 47011 Valladolid \\ leire.gomez@hmca.uva.es | Orcid: http://orcid.org/0000-0002-6436-0297 \\ Elena Medina de la Viña, Universidad Rey Juan Carlos, Camino del Molino, s/n, \\ 28943 Fuenlabrada, Madrid \\ elena.medina.delavina@urjc.es | Orcid: http:/orcid.org/0000-0003-2685-1033
}

DOI: http://dx.doi.org/10.12795/Ambitos.2019.i46.02

\begin{abstract}
Resumen
La televisión continúa siendo el medio más consumido por los jóvenes del siglo XXI, aunque ha ido perdiendo liderazgo frente a otros soportes y pantallas. Este público muestra poco apego hacia la televisión convencional y hace del medio un uso de mero entretenimiento (López Vidales y Gómez Rubio, 2014, p.334). El objetivo principal de este trabajo ${ }^{1}$ es aproximarnos a los formatos televisivos más consumidos por los jóvenes españoles de 20 a 24 años; mediante el estudio de las parrillas televisivas de
\end{abstract}


la última temporada (2018-2019) y el análisis cualitativo de las propuestas más destacadas se establecerán las claves del éxito de sus programas preferidos. La hipótesis de partida es que el reality show constituye la base de una mayoría de formatos del macro-género Entretenimiento (Prado y Delgado, 2010) que fidelizan a los jóvenes mediante una estrategia de empoderamiento del usuario facilitada por los canales de participación generados por el formato. La clave de la telerrealidad actual está en la capacidad de decisión de los usuarios anónimos que evalúan el talento, construyen estrellas y forjan héroes.

\section{Abstract}

Television is still the most consumed media by the young people of the 21st century, although it has been losing leadership compared to other supports and screens. This public shows little attachment to conventional television and uses the media as a mere entertainment (López Vidales and Gómez Rubio, 2014, p.334). The main objective of this work is to approach the most consumed television formats by young Spaniards aged 20 to 24 years old; Through the study of television broadcasting of the last season (2018-2019) and the qualitative analysis of the most outstanding proposals, the keys to the success of their favourite programs will be stablished. The initial hypothesis is that the reality show constitutes the basis of the majority of formats of the macrogenre Entertainment (Prado and Delgado, 2010) that build loyalty from young people through a user empowerment strategy facilitated by the participative channels generated by the Format. The key to current reality is in the decision-making capacity of anonymous users who evaluate talent, build stars and forge héroes.

Palabras clave: Jóvenes, telerrealidad, formatos audiovisuales, televisión, participación.

Keywords: Young people, real television, media formats, television, participation.

\section{INTRODUCCIÓN: JÓVENES Y CONSUMO TELEVISIVO EN 2019}

Los jóvenes son el colectivo que menos televisión consume en la actualidad. Según los últimos datos de audiencia, en 2018 los jóvenes de 14 a 24 años supusieron el $11,3 \%$ de los televidentes, frente al $24,4 \%$ que representó el colectivo compuesto por aquellos de 65 años o más edad, que fue el grupo que lideró el consumo televisivo en este mismo año (AIMC, 2019), con un promedio diario de seis horas y cuatro minutos delante de esta pantalla (Barlovento Comunicación, 2019).

Entre los principales motivos para esta desafección juvenil hacia el medio televisivo se encuentra el hecho de que no se sienten atraídos por sus contenidos (López Vidales y Gómez Rubio, 2014, p. 332-333), al tiempo que Internet y las nuevas tecnologías transforman el consumo de productos audiovisuales, proporcionándoles una "oferta 
variada, de acceso ilimitado, inmediato y ubicuo" que les permite elegir aquellos contenidos que desean visualizar cuándo y dónde deseen (García, Tur y Pastor, 2018, p. 31). Junto a esto, hay que tener en cuenta que los hábitos mediáticos de los jóvenes son sensiblemente diferentes al del resto de la población, ya que el mayor uso de Internet de este perfil se produce a partir de una menor aproximación media diaria a la mayor parte de los medios, no sólo televisión (Reinares, 2010, p. 73). Así, diferentes encuestas y estudios realizados recientemente señalan que siete de cada diez jóvenes españoles reconocen visualizar contenidos diariamente en YouTube, frente al $20 \%$ que se decanta por la televisión tradicional. Sin embargo, el $51 \%$ de los encuestados asegura que "regresaría" a la televisión convencional "siempre y cuando se programara algún espacio interesante", mientras el $42 \%$ se muestra reacio a engancharse de nuevo a cualquier programa o serie. Entre los aspectos más negativos de la televisión, los jóvenes encuestados mencionan su programación (47\%) y la imposibilidad de poder elegir los contenidos (38\%), así como la falta de interacción con el medio (11\%) (El Confidencial, 2017). No en vano, para los jóvenes,

la televisión tiene, cada vez más, un valor instrumental y, cada vez menos, una autoridad indiscutible, como sí sucedía entre generaciones anteriores. Los llamados nativos digitales, acostumbrados a los códigos mediáticos y la interacción con y desde las pantallas, quieren y saben controlar mejor los universos mediáticos, así como utilizarlos para el cumplimiento de sus propios fines (Baladrón, 2012, p.52).

En el mismo sentido apuntaban los resultados arrojados por el Observatorio del Ocio y el Entretenimiento Digital en su estudio Preferencia juvenil en nuevos formatos de televisión: consumo en jóvenes de 14 a 25 años (Cód. OCENDI010911) que se inició en 2009 y que se mantiene abierto como una de sus líneas fundamentales de investigación. En él se destacaba el hecho de que cuando los jóvenes encienden el televisor, lo hacen para visionar programas que responden a géneros muy concretos, que varían dependiendo de su edad, percibiendo notables diferencias entre aquellos que entonces tenían entre 14 y 17 años, y que actualmente conforman la llamada Generación Z (Horovitz, 2012) o Centennials (ReasonWhy, 2017), y los que contaban entre 18 y 25 años, que constituyen ahora los llamados los Millennials (Strauss y Howe, 2000). Los formatos televisivos favoritos para este público se situaban en los siguientes términos: de 14 a 17 años preferían los programas dramedia (dramedy) $(17,3 \%)$, las sitcom $(16,4 \%)$, el cine $(16,3 \%)$ y los docu-realities $(6,8 \%)$, mientras que de 18 a 25 años sus gustos prácticamente se monopolizaban en torno a las series $(29,7 \%)$ y el cine $(23,9 \%)$, seguidos, pero en mucha menor medida, por las sitcom $(6,4 \%)$ y los realities $(6 \%)$.

Casi una década después, cabe preguntarse si los gustos y preferencias en consumo televisivo de la Generación $Z$ han cambiado ahora que estos jóvenes ya se han 
iniciado, o están a punto de hacerlo, en la edad adulta, y si, en caso afirmativo, sus preferencias se asemejan a las que manifestaban quienes a principio de esta década tenían la misma edad que ellos ahora. Hay que tener en cuenta que, en aquel momento, los entrevistados demandaban más innovación en formatos televisivos aprovechando la implantación de la TDT y la proliferación de pantallas - que contribuyeran a una mayor variedad en la oferta, puesto que se quejaban de que todas las cadenas "hacían lo mismo a las mismas horas" (López Vidales et al. 2013, p. 197). En las preguntas abiertas que se les formularon hace ahora ocho años, algunos resumían esta opinión asegurando "que hay muchos canales, pero muy pocos contenidos que valgan la pena" y esperaban que "con la TDT se elaboren contenidos más específicos para los diferentes tipos de público" (López Vidales et al. 2011).

A la vista de los datos, se constata que es una vez abandonada la adolescencia cuando los jóvenes comienzan a interesarse en mayor medida por los programas de actualidad, información y opinión, en detrimento de una programación que apueste única y exclusivamente por el entretenimiento, que es la televisión preferida por los individuos de menor edad. Cabe destacar que, para los más jóvenes, ficción (15,9\%), sucesos $(14,6 \%)$ y fotografía/imagen $(13,3 \%)$ eran los contenidos o elementos que deberían incluirse siempre en los formatos televisivos, mientras que la información $(9,6 \%)$, las opiniones $(9 \%)$ y las entrevistas $(7,1 \%)$ representaban los factores menos valorados. Por el contrario, para el segmento de edad, entre los 18 y los 25 años, la información $(17,7 \%)$ y las entrevistas $(17 \%)$ eran los puntos más citados, seguidos por aquellos espacios que contuvieran opinión (12,3\%) y fotografía/imagen (11,7\%). Para estos espectadores, la ficción $(9,3 \%)$ y los sucesos $(6,5 \%)$ eran los contenidos menos valorados.

\section{PLANTEAMIENTO DE LA INVESTIGACIÓN: OBJETIVOS, HIPÓTESIS Y METODOLOGÍA}

El objetivo fundamental de nuestro análisis consiste en averiguar cuáles son los contenidos televisivos más consumidos por los jóvenes españoles de hoy y analizar qué les ofrecen esos formatos, cómo son y qué transmiten a la actual Generación Z. Trataremos de aproximarnos a la motivación juvenil hacia estos contenidos teniendo en cuenta, especialmente, aspectos como la narrativa utilizada, la estructura de los formatos, el estilismo de su puesta en escena y, en definitiva, las claves del éxito de estos programas ${ }^{2}$.

En un contexto digital multiconvergente, el medio televisivo ha ido reformulando sus contenidos para adaptarlos no solo a las nuevas condiciones tecnológicas, sino a las demandas de las nuevas generaciones. Lejos de suponer la eclosión de nuevos formatos plurales y diferenciados, esta adaptación ha provocado, entre otros, un amplio proceso de hibridación de géneros e ideas de programas que a veces ha dificultado la innovación creando largos espacios en parrilla que también se asoman a 
otras ventanas con la intención de propiciar la participación efectiva de la audiencia. La participación en los contenidos es una de las claves del éxito de los nuevos formatos para lo que se despliega, desde producción, una estrategia destinada al empoderamiento de los sectores más esquivos al consumo tradicional de televisión, pero más familiarizados con los canales participativos. Los jóvenes se sienten, en el consumo de estos contenidos, no solo sujetos activos de la distribución, sino protagonistas del acontecer interno del programa e incluso del destino de los personajes del relato y hasta del relato en sí. Las nuevas narrativas transmedia son un ejemplo relevante de parte de esa estrategia.

En consecuencia, en este estudio partimos de la siguiente certeza: los jóvenes españoles de entre 20 y 24 años han demandado en los últimos años contenidos nuevos con más cultura, más humor y más entretenimiento en general. Valoran menos la información, la opinión y las entrevistas. Para ellos lo fundamental es la imagen, la música y la posibilidad de conexión y participación en cualquier momento, bien sea a través de comentarios o de compartir piezas a través de las redes sociales.

Teniendo en cuenta esta premisa, planteamos como hipótesis principales las siguientes:

1. El formato que más atrae y más siguen los jóvenes de la Generación $Z$ es el reality en sus versiones talent show o game. De hecho, la telerrealidad y el juego de rol abundan en las series de ficción y el cine que consumen las nuevas generaciones.

2. La narrativa de estos programas es muy compleja, pero se percibe escasamente guionizada, poco lineal y con una estructura abierta que acompaña al relato de "sucesos vitales". En el formato abundan la improvisación, las pruebas de convivencia y/o superación, relatos vitales de gente desconocida, emociones y grandes espacios.

3. El macrogénero Entretenimiento es el dominante en sus preferencias actuales, en detrimento de la información e incluso la ficción televisiva lo que ha de tener consecuencias inevitablemente en la concepción futura de los medios de comunicación.

Para el desarrollo de la investigación, elegimos una metodología cualitativa dividida en varias fases. En primer lugar, y partiendo de la investigación precedente de OCENDI, efectuamos una revisión de la literatura científica existente sobre este objeto de estudio en nuestro país que nos conduzca a una primera radiografía sobre qué demandaban a principios de la presente década los jóvenes españoles de 14 a 25 años en cuanto a formatos y programas preferidos para su consumo televisivo. Seguidamente, y dentro de esta primera fase introductoria, acudimos a los últimos datos sobre audiencias mediáticas procedentes de las fuentes más relevantes, Kantar Media, Barlovento Comunicación, el EGM y Dos30, todos ellos de 2019. De aquí 
extraemos los datos recientes, semana a semana, de cuáles son los contenidos programáticos con más seguidores jóvenes y en qué canales de televisión se emiten. En esta primera fase del proceso, el propósito fue la comparación de los datos recogidos en la investigación de 2010-2013 por el Observatorio con los registrados en 2019 por las empresas mencionadas.

En una segunda fase, y una vez realizado el estudio comparativo de los primeros resultados, se procedió a seleccionar los programas que reflejan un mayor éxito entre los jóvenes y se les aplicó un análisis de contenido a los formatos de emisión con la finalidad de definir su estructura, organización de elementos y estilo.

Por último, se estudia la narrativa por separado, para tratar de acercarnos a la motivación subyacente que provoca que los jóvenes los elijan y consuman, además de observar la estrategia del programa y los valores que transmite.

Las preguntas de investigación de las que partimos fueron las siguientes:

1. ¿Qué hace que estos programas enganchen a la audiencia juvenil y dónde están los elementos de éxito?

2. ¿Qué les aportan estos formatos en cuanto a información, valores o comportamientos?

\section{LOS PROGRAMAS DE TELEVISIÓN PREFERIDOS POR LOS JÓVENES}

La cadena de televisión más vista hoy por los jóvenes españoles de entre 13 y 24 años es Telecinco con una cuota de pantalla del $11,8 \%$, seguida por los canales temáticos con un $10,1 \%$, y se confirma una marcada tendencia hacia el consumo de cadenas temáticas de pago, tal y como manifiestan los datos del pasado mes de abril: son las cadenas líderes en jóvenes de 13 a 24 años (Barlovento, 2019).

Los programas con mayor audiencia juvenil de entre 20 a 24 años, según el ranking más reciente, son: Gran Hermano (con todas sus variaciones, como Gran Hermano VIP y Gran Hermano VIP Express; Reality de convivencia, en Tele 5), Operación Triunfo (Talent show, en TVE), La Voz (Talent show, en Antena 3TV) y Supervivientes (Reality de supervivencia, en Tele 5). Además de estos, El Hormiguero (Talk show/Late show por emisión, e hibridado con game, en Antena 3TV) y Mujeres, Hombres y viceversa (Dating game, en Cuatro).

Los cuatro programas más vistos se corresponden con el formato Reality show que se caracteriza por hacer de la realidad un espectáculo televisivo, una realidad que se basa en la vida cotidiana de la gente común. Su origen está en la evolución y fusión de los programas de variedades y los informativos, y se proyectan hacia los sucesos y las relaciones personales (Saló, 2003). 
Los realities son el máximo exponente de la telerrealidad -programas de la neotelevisión- y se pueden entender como "un género televisivo en el cual se muestra lo que le ocurre a personas que no interpretan un determinado personaje" (Estupiñán, 2010, p. 94). Es difícil establecer en la actualidad una clasificación de estos formatos, pues "la telerrealidad nos ofrece un amplio abanico de variaciones y combinaciones que, además, se reinventan constantemente” (Hidalgo-Marí, 2018, p. 625). A grandes rasgos se puede hablar de tres tipos de formatos de telerrealidad: los que presentan la observación de un grupo de personas sin intervención de presentadores; aquellos en los que se filma a personas sin su conocimiento; y los concursos de telerrealidad en los que los y las participantes persiguen un premio. Es en este punto en el que podemos "encontrar la transformación del género de telerrealidad en lo que hoy conocemos como los realities show" (Estupiñán, 2010, p. 96). León (2009, p. 15-16) hace una clasificación desde el punto de vista de su contenido, lo que da como resultado cinco tipos de realities: de accidentes y crímenes, de ayuda social, intervenciones en la vida de las personas, de convivencia y relaciones personales y por último, de formación artística; por otra parte, "Desde el punto de vista del formato, los más destacados son los siguientes: Documental [...], Docu-soap o docu-novela $[\ldots]$, Concurso".

\subsection{Producción, estructura y elementos definitorios}

Dada la actual hibridación de géneros y formatos resulta muy difícil atenerse a una clasificación cerrada que nos permita establecer cuáles pertenecen exclusivamente al género fundamental para nuestro estudio, el entretenimiento. Todos los programas de este macro-género contienen elementos que "son comunes a varios formatos característicos de esta modalidad, en especial, reality shows, juegos-concursos, talk shows y series" (Imbert, 2005, p.161). Pero, además, el factor entretenimiento está presente en la mayor parte de los contenidos televisivos, pues "aunque la televisión puede usarse con finalidades diversas, ella misma tiende a ser comunicación entretenida" (García Avilés, 2007, p. 50). Aún con todo, trataremos de analizar brevemente los formatos más vistos por los jóvenes y conocer los elementos comunes que los identifican como preferidos por esta capa de la población.

- Gran Hermano. Creado por la empresa holandesa John de Mol Produkties, posterior Endemol entre 1997 y 1999, es el programa de telerrealidad por excelencia. Su producción corre a cargo de Zeppelin TV, perteneciente al grupo Endemol Shine Iberia, para Mediaset. El formato se basa en el encierro de varios participantes elegidos en un casting previo que deberán convivir aislados y superar una serie de pruebas; las cámaras y micrófonos instalados en el interior de la casa serán testigo de sus relaciones; el público tiene la capacidad de expulsar a los participantes nominados por sus propios compañeros hasta que uno de ellos consiga el premio final. El programa se emite en Telecinco desde el 2000 y ha conocido diversas variantes que 
actualizan el formato: Gran Hermano Vip, El Reencuentro y Gran Hermano Dúo (2019). Para Terribas y Puig este programa "constituye un ejemplo significativo de la hibridación de géneros en el contexto televisivo actual" (2001, p. 5); según estas autoras Gran Hermano integra diversos géneros: concurso, telenovela, documental, reality show, talk show, docudrama, reportaje y magazine. Siguiendo la clasificación establecida por León, su contenido lo sitúa como reality de convivencia y relaciones personales y en cuanto al formato como concurso. Según datos de Barlovento Comunicación, Gran Hermano Dúo se sitúa en cinco posiciones de las diez emisiones más vistas en marzo 2019, solo por detrás de cuatro retransmisiones deportivas, Clasificación para la Eurocopa, y de la emisión de Salvados del Papa Francisco, con una cuota del $18,4 \%$ de pantalla, y un número de espectadores estimados entre los 3 y 4 millones. El cierre de la sexta edición de Gran Hermano VIP de 2018 según Barlovento Comunicación y Dos30' alcanzó una cuota del 32,6\% y 3.649.000 espectadores. También hay que señalar "su espectacular seguimiento entre los jóvenes de 13-24 años (33,8\%) y de 25-34 años (37,1\%)" (Molina, 2018).

- La Voz. Se trata de un formato creado también por John de Mol desde su empresa Talpa; se emitió por primera vez en 2010 y al igual que Gran Hermano es un formato de éxito que disfruta de numerosas adaptaciones internacionales. En España se emitió en Telecinco desde 2012 a 2017 producido por Boomerang TV. En 2018 Antena 3 compró los derechos del formato que se emite en la actualidad producido por Veranda TV, empresa participada por el Grupo Godó y el Grupo Boomerang. El formato se basa en un concurso de talentos en el que solo importa la voz de los participantes; el desarrollo de la temporada se organiza en varias fases: en la primera, los jueces seleccionan a los participantes exclusivamente por su voz, ya que permanecen de espaldas a los concursantes y se darán la vuelta cuando les guste una voz; a continuación, los seleccionados volverán a repetir la prueba a ciegas, esta vez los jurados se darán la vuelta cuando eligen a su "tutorizado". En la fase de las batallas, el coach expulsa a un candidato/a y finalmente llega la fase de las galas decidiéndose el ganador mediante el voto del espectador. Según datos de Barlovento Comunicación, las Audiciones de La Voz fue el programa más visto de Antena 3 en enero de 2019 con una cuota del $25 \%$ y en el ranking general de emisiones del mismo mes aparece en tercer lugar en lineal y en el quinto en diferido. Según Quintas Froufe y González Neira, La Voz tiene muy buenos resultados en audiencia social y concluyen que también es el espacio con mayor número e incremento de seguidores, "asimismo su presentador y dos miembros del jurado están entre las tres cuentas que más participan en Twitter" (Quintas Froufe y González Neira, 2014, p. 88). Este programa obtiene en su estudio los mejores resultados tanto en audiencia real como en audiencia social. La empresa de medición de audiencias Kantar Media clasifica este formato como Talent musical, mientras que según la clasificación de León se definiría como de formación artística y concurso en cuanto al formato. 
- Supervivientes. Es un formato de telerrealidad de supervivencia creado en 1994 por el británico Charlie Parsons con su empresa Planet 24. La primera edición se realizó en 1997 para la televisión pública sueca; en 1998 Mark Burnett lo licenció registrándolo como Survivor para la CBS norteamericana. El éxito del formato se extendió a todo el mundo. En España se emitió por primera vez en Telecinco en el año 2000 producido por Globomedia (2000-2005) y posteriormente por Magnolia TV (20062015) y Bulldog Producciones (desde 2016 a la actualidad). En 2003 Antena 3 se hace con los derechos del formato. En la actualidad lleva 18 ediciones alternando programas con anónimos y con famosos. Según FormulaTV (2018) la edición de 2018 ha tenido un $29,2 \%$ de share, el más alto de la historia del formato en España y señala que "el programa consigue un alto $34,3 \%$ de share medio entre los espectadores de 13 a 24 años mientras que el dato baja levemente entre el público de 4 a 12 años $(27,1 \%)$ y el de 25 a $44(27,2 \%)$ ". Esta cuota en jóvenes aumenta significativamente en la última gala (mayo 2018), consiguiendo un 46,5\% entre los jóvenes de 13 a 24 años (Formula TV según datos de Dos30, 2018) y confirma la tendencia, pues la temporada anterior (2017) este formato ya destacaba entre el público de 13 a 24 años con un share de 25,6\% (Quijorna, 2017). Se clasificaría como reality de convivencia y relaciones personales y concurso siguiendo la clasificación de León.

- Operación Triunfo. Fue creado por la productora española Gestmusic, en la actualidad integrada en el Grupo Endemol Shine Iberia. Se emitió por primera vez en 2001 en Televisión Española y tuvo un reconocido éxito internacional exportándose hasta el momento a 31 países. Según Gestmusic Endemol, se trata de un formato que con su mezcla de concurso y reality ha revolucionado los programas de entretenimiento musical y ha cautivado a la audiencia a nivel mundial. Se encuadra en lo que León define como reality de formación artística y concurso. El concurso de talentos está claramente definido ya que en cada temporada habrá un solo ganador. En cuanto a la parte reality consiste en una convivencia de tres meses por parte de los concursantes, en la cual

los jóvenes trabajan, se esfuerzan y se preparan para las actuaciones en las galas que se transmiten en directo para que la audiencia pueda seguir el desarrollo y la evolución artística de los participantes. Artistas de reconocimiento nacional e internacional visitan la Academia, departen y aconsejan a los chicos en su trabajo, lo que produce un cierto clima de sorpresa y expectación en la audiencia, que no conoce a priori quiénes serán los visitantes (Cáceres, 2002).

\section{Según Pérez,}

el $22 \%$ del volumen total de audiencia de OT 2017 provino de las plataformas digitales. Es decir, casi una cuarta parte del consumo de la edición se produjo online, principalmente en YouTube, pero también en RTVE.es [...]En este 
consumo destaca el público joven (18-24 años), que fue desde el principio el gran objetivo de los productores de Operación Triunfo (2018).

En cuanto a 2018, "El tiempo total de visionado online es un $60 \%$ mayor que el del año pasado" (Pérez, 2018).

Gran Hermano, La Voz y Supervivientes responden a formatos de éxito probado; no son programas originales, sino una adaptación de formatos internacionales. En el caso de Operación Triunfo, también hablamos de un formato de éxito, pero diseñado en España, es decir, la primera apuesta por el programa es de formato original cuyo éxito permite la exportación internacional. En definitiva, los cuatro programas forman parte del nuevo estilo de programación surgido a comienzos de 2000 y basado en la importación de formatos de éxito. Todos ellos han sido estudiados en numerosas ocasiones en los últimos años, al igual que lo ha sido el formato reality. Lo que nos interesa aquí es dilucidar qué consigue atrapar a los jóvenes de hoy y qué valores les transmite, por lo que nos centramos en aquellos aspectos que nos conduzcan hasta el objetivo.

\subsection{Narrativa y participación del espectador como clave del éxito}

Tal y como puede comprobarse, los elementos centrales de estos formatos son la música, la imagen como prueba de la "realidad", y el juego vehiculado a través del concurso. Los protagonistas no son personajes creados/ficcionados, sino recreados por la audiencia, con la ayuda de producción, una audiencia que deposita sobre cada uno de ellos su apuesta por el éxito final. A la autenticidad del relato contribuye la estética del programa mediante las imágenes -está pasando- en muchas ocasiones en directo. Pero el tiempo del programa es frecuentemente televisivo, aunque con apariencia real, que se extiende además por multitud de momentos televisivos ajenos al programa (long tail) y se multiplica en los distintos canales de participación que ponen a disposición de la audiencia todos los formatos, esto es, redes sociales y páginas web específicas dentro de las cadenas, además de los canales de YouTube asociados al formato para la distribución de fragmentos seleccionados en otras pantallas.

Otros elementos relevantes del formato son el narrador testigo (a veces omnisciente), la realización multicámara, la utilización de planos subjetivos en realización y los espacios amplios pero cerrados, con libertad controlada para los personajes del relato.

Las claves del éxito de estos programas podemos encontrarlas en la selección de los personajes: son reales, ciudadanos que traslucen su vida en una casa, una academia o una isla. Como si de un set de televisión se tratara, los personajes descubren su vida, muestran sus relaciones, su intimidad, exponen, en definitiva, su privacidad a los ojos del espectador al que convierte en cómplice del relato. Sin embargo, esta 
disposición encuentra hoy su fortaleza en las redes sociales donde se brinda al cotilleo público el ámbito privado de la gente común. Al voyerismo se une la participación por varios canales digitales a través de los que se fomentan los comentarios sobre las actuaciones y actitudes, las críticas, la humillación y las apuestas sobre cuál será el ganador; se generan odios y filias en torno a cada personaje que se ve expuesto al escarnio público mientras resuelve un determinado rol que le va asignando la audiencia. La narrativa contiene una distribución de estos roles desde producción, entre los que se pueden diferenciar el "héroe", el destinador, el destinatario, el narrador o el colaborador en el relato. También se asigna el poder, factor clave en el formato para motivar a la audiencia, y lo hace a favor de los profesores, los coaches, el público en plató, los espectadores y los usuarios (Oliva, 2012). Como en todos estos programas se persigue la popularidad y el éxito, es necesario construir/moldear al personaje protagonista, bien sea un héroe, una celebritie o una estrella, construcción en la que interviene el estilismo con el fin de crear modelos a seguir para público, un público que a su vez se convierte en fan y participa en una comunidad virtual desde donde puede presionar a favor o en contra de un personaje y balancear el resultado final hacia uno u otro ganador del concurso. Esta manifestación del poder del usuario sobre el individuo aislado que lucha por ganar es, sin duda, una de las motivaciones más notables hacia este formato de entretenimiento.

Además de este poder de la audiencia, casi siempre en forma de votaciones del público y los espectadores, los formatos preferidos por los jóvenes muestran otras claves en la narración que se estiman valores sociales, culturalmente reconocidos como positivos: el esfuerzo, el trabajo, el sacrificio, la disciplina, la exigencia, la constancia y la sinceridad. En función a estos valores, se pretende transmitir una representación meritocrática de la sociedad por la cual, quién tiene talento y trabaja duro, llega a donde quiere (Oliva, 2012). En este punto, aparecen otras dos señas de identidad del mensaje representado en estos formatos; de un lado, el reconocimiento del talento de los personajes y la pugna por ser el mejor; de otro, la soledad del individuo frente a la competencia. De nuevo aquí, la audiencia interviene en el juego, desplegando su poder y salvando o condenando a un determinado personaje. El "valor" representado de la singularidad del individuo frente a "las masas", es un elemento narrativo fundamental de la forja del héroe, detrás de cuyo significado se sitúa el individualismo, característica fundamental de la actual evolución social (Grossmann y Varnum, 2015) y una zona de confort para las últimas generaciones de jóvenes. En el mismo sentido, la clave más duradera es que el fin es conseguir el éxito, sea como héroe o como estrella, y en cualquier caso, alcanzar la popularidad.

\subsection{La estrategia en redes sociales}

Actualmente, el éxito de un programa de televisión no depende únicamente de la audiencia convencional, sino también de la social que, poco a poco, ha ido adquiriendo 
una relevancia destacada, especialmente, entre el público más joven acostumbrado al consumo simultáneo de varias pantallas y al multitasking (Gómez Rubio y López Vidales, 2015, pp. 138-139). De ahí que los programas preferidos por los jóvenes sean a menudo los más seguidos en redes sociales, un éxito que no sólo depende del "activismo" de la audiencia, sino también de la estrategia desarrollada por los diferentes canales y programas.

Así, por ejemplo, Gran Hermano es el espacio "rey" en redes sociales, siendo capaz de "generar picos de conversación más altos que un debate político". De hecho, durante la emisión de Gran Hermano 17, se contabilizaron más de 400.000 usuarios únicos, más de 200.000 menciones de media durante una gala y más de 7.000 comentarios por minuto. Entre las claves para lograr la participación de los espectadores, la directora de casting de Gran Hermano y Social Media Manager en Zeppelin, Pepa Álvaro, señala los mensajes centrados en los personajes-concursantes y en los presentadores (Séntisis Analytics, 2016).

Operación Triunfo es otro de los programas que no escatima esfuerzos a la hora de contar con "una marcada estrategia transmedia" para conectar con el público juvenil. Entre sus primeros objetivos de la última edición figuraba la promoción del espacio y la creación de expectación entre sus seguidores habituales -y seguidores potencialesantes de su estreno. A partir de aquí, y en aras a incrementar el número de fans lo máximo posible, el espacio se centró en fomentar en estos la necesidad de acceder cada vez a más material relacionado con el formato, material que se ponía a disposición de los seguidores de manera inmediata. Esto, unido a la posibilidad de acceder a piezas audiovisuales del reality a través de YouTube -el canal 24 horas de Operación Triunfo- logró 85 millones de visualizaciones durante los meses que duró su emisión (Alonso López, 2018).

La Voz, por su parte, fue Trending Topic nacional y mundial en su estreno, así como líder del share social con picos del $73 \%$, y la emisión más comentada en Twitter. En menos de 48 horas desde su estreno, las cuentas oficiales del programa en las redes sociales registraron una subida del $55,7 \%$, que ascendió hasta el $75 \%$ durante la primera semana, con más de 38 millones de impresiones acumuladas en los perfiles. De las tres redes con mayor número de seguidores -Facebook, Twitter e Instagramesta última ha sido la que ha contado con una irrupción más fuerte, con cerca de 100.000 seguidores; entre sus principales contenidos destaca 'El diario de La Voz' (lasexta.com, 2019).

En el caso de Supervivientes, la estrategia del programa en las redes fue más allá de la autopromoción del espacio. Sus responsables no se limitaron a colgar vídeos que narrasen lo sucedido en el programa, sino que crearon y compartieron contenido exclusivo que fue desde memes a montajes que "amplifican el debate sobre el show" y 
que "generan una curiosidad extra, que atrae por estas redes sociales a nuevos espectadores que no estaban sintonizando la emisión en directo y terminan enchufando Telecinco" (Terán, 2018). Esta táctica ha servido para que el programa sume usuarios y seguidores en Twitter e Instagram de la mano de contenido "propio, travieso y realista" (Terán, 2018) que no sólo conecta con el espectador, sino que logra que éste tuitee y retuitee el contenido (Terán, 2018).

\subsection{Valores detrás de los formatos: entonces, ¿qué transmiten?}

Los realities seleccionados poseen, a pesar de la apariencia contraria, una narrativa compleja. En varios casos, además, el reality se convierte en un killer format que estructura el grueso de la parrilla de las cadenas que lo emiten (Carrasco, 2010, p. 178) por lo que la abundancia de imágenes e informaciones relacionadas con el contenido del programa es muy significativa. Sin embargo, no debemos olvidar que se trata de programas de entretenimiento y así son consumidos por la audiencia.

A la luz de los elementos estudiados, se deducen otros intrínsecos al relato que nos conducen al significado de esta puesta en escena. Un resumen previo, significante, nos lleva a interpretar el objetivo valorable que vislumbran los espectadores:

- OT: a través del esfuerzo y el sacrificio, un individuo con talento puede ser una estrella

- GH: todos tenemos problemas y el trabajo no es lo más importante, sino la cara oculta y los sentimientos del individuo en su vida cotidiana, su sufrimiento, sus relaciones, su forma de actuar le llevarán a ser más popular

- La Voz: el talento no es suficiente si no está guiado por una autoridad; no supone trabajo en equipo para los participantes, solo para los coach, pero la finalidad es la misma, alcanzar la fama

- Supervivientes: el talento hay que aplicarlo a las circunstancias adversas para competir contra los demás; la destreza y el juego personal son fundamentales para alcanzar el poder.

Podemos deducir, por tanto, qué es común al relato de todos ellos: el establecimiento de una autoridad en la escena, bien el profesor, el coach, el maestro o figura similar; el aprendizaje, cuyo proceso se cierne sobre la acción de mostrar el talento o las habilidades que sobresalen de cada uno; la búsqueda del éxito, sea profesional o social, que conduce a un estatus superior que proporciona además rentabilidad económica; el aislamiento del individuo, como estado necesario para la transformación del héroe o la estrella de anónimo a popular; y la competitividad, como camino seguro hacia el éxito, el poder y el dinero.

Al espectador, como al personaje del reality, se le convence de que el talento no es suficiente; como hay una autoridad, hay seres obedientes que deben aprender a 
canalizar ese talento y para ello se exige maleabilidad (Oliva, 2012). El ganador ha de formarse en el aprendizaje y para que conduzca al éxito ha de crear también una imagen personal de triunfador. En la construcción de esta imagen juega un papel fundamental la idea de que no solo se aprende para ser un ganador, sino también para ser uno mismo. Por último, la competitividad se usa para alcanzar el poder, pero en este estadio, el poder está compartido: el talento no es suficiente para alcanzar el éxito, tampoco el esfuerzo o la suerte; ahora hay que "conectar" con el público usuario del programa que es quien tiene el mando. Es el usuario el que tiene la última palabra sobre la deriva de los concursantes, de los personajes de cada reality, o al menos es la idea que se desprende de la estrategia productiva del formato y ahí es más que probable que sea donde radique el éxito de audiencia con los jóvenes.

Desde un punto de vista simbólico, los logotipos, isotipos e imagotipos de los programas refuerzan los valores antes señalados: los de OT y La Voz son muy parecidos: una mano con un micro en alto hasta 2017, en que la mano se estiliza y muta en la T de triunfo; en La Voz también aparece una mano con micrófono y signo de victoria, aunque diversifica las versiones del logo y en ocasiones la $\mathrm{V}$ de victoria la hacen los coach/preparadores. En ambos casos, triunfo y victoria aparecen como elementos definitorios del programa. GH tiene un ojo como logo/isotipo; aunque hay variaciones en su imagen, lo siguen manteniendo como referente; su pupila roja identifica tanto el botón rojo de grabación como el objetivo de una cámara. El logo de Supervivientes no es un ojo pero se encierra en una elipse cuya forma lo recuerda; en ambos casos la alusión al voyeurismo, a la intrusión del espectador en la vida de los participantes a través de las cámaras, testigos permanentes de lo que sucede entre los individuos participantes, es evidente; al igual que el Gran Hermano de la obra de Orwell (1984) vigilaba constantemente a los ciudadanos y conocía tanto sus logros como dudas y desobediencias, el programa y el espectador vigilan y comprueban que las actuaciones de los y las participantes les permitirán fracasar o vencer.

\section{DISCUSIÓN DE RESULTADOS Y CONCLUSIONES}

Los jóvenes españoles de entre 20 y 24 años son un sector poblacional poco fiel a los medios de comunicación tradicionales. En el caso de la televisión, constatan una tendencia a la baja en el consumo de los productos audiovisuales de su programación, a la par que muestran unas preferencias centradas casi exclusivamente en el género entretenimiento. Esta tendencia comenzaba a señalarse a principios de la presente década y así lo reflejaron, tanto los estudios de audiencias más relevantes, como la investigación llevada a cabo por OCENDI de 2010 a 2013, cuyos resultados apuntaban a un cambio entre las preferencias de formatos televisivos entre los Millennials y la Generación $Z$ en el sentido de un progresivo abandono de formatos tradicionales, especialmente los informativos, en favor de programas de entretenimiento como deportes, talk-shows y telerrealidad. 
Para la nueva generación de jóvenes, el formato televisivo "rey" es el reality show, un híbrido convertido en macrogénero catódico, que se presenta en múltiples variantes, pero que es en las versiones game, talent o dating, donde encuentra su mayor índice de seguidores entre este segmento poblacional. El relato fundamental en el que se basan estos programas tiene como epicentro el "suceso vital" cargado de emotividad, donde se muestran desde la cara oculta de los ciudadanos anónimos y sus sentimientos, hasta las posibilidades de triunfo del talento individual, las capacidades de supervivencia en condiciones extremas y el largo camino hacia la popularidad -la fama-, todo ello enmarcado en un contexto competitivo que presiona para que se produzca un resultado jerarquizado, un ranking, donde se ordenan ganadores y perdedores.

En la estructura del reality los elementos visuales, la música, el humor, la emoción, el ritmo dinámico, la sorpresa, la improvisación y la escenificación de situaciones a través de pruebas, contribuyen a una puesta en escena en la que se advierte una cierta tensión entre público y usuarios por determinar quién tiene el poder de convertir a uno de los participantes en el show en ganador. En la pugna por este poder, la estrategia desplegada por los productores en las redes sociales es fundamental para que la audiencia más joven perciba que con su participación activa puede balancear el resultado a su antojo, aunque sea una ilusión. Y ocurre también, que, en ocasiones, se cosifican las personas, se convierten en una suerte de avatares con un determinado rol en el juego para que el público pueda observar su comportamiento y participe en su destino final. El interés para el espectador está en contemplar, a través de personajes no ficcionados, las emociones de la vida real. La apuesta actual pasa por incrementar el grado de competitividad (concurso) en el formato, el de ficcionalización de la puesta en escena (cercano a la telenovela) y el de game (rol). Todo ello, además, con una doble recompensa para los protagonistas de estos espacios, ya que al incentivo del premio económico, se le suma, en el caso de personajes anónimos, la fama.

Un vistazo al contexto audiovisual general de los últimos años nos lleva a observar cómo la industria ha puesto en circulación productos de línea similar en otros sectores, como es el caso del cine, donde la saga distópica de "Los Juegos del hambre" (Jacobson, 2012-2015) o las películas de la factoría Marvel (MCU, 2008-2019) han enganchado a un público juvenil que ha encumbrado además a los videojuegos como protagonista del ocio digital de nuestro tiempo. Llegados a este punto, es difícil concretar en pocas líneas los valores que transmiten desde estos espacios televisivos, pero parece plausible apuntar al fomento del individualismo y el actual sistema de mercado, donde la lucha por ser el "mejor" y destacar por encima de los demás es la clave del triunfo. 


\section{Notas}

${ }^{1}$ La aportación se encuadra dentro de la investigación Preferencia juvenil en nuevos formatos de televisión: consumo en jóvenes de 14 a 25 años iniciada en 2010 por el Observatorio del Ocio y el Entretenimiento Digital y que representa una de las principales líneas de trabajo del GIR "Cultura, Innovación, Creatividad y Participación social en Comunicación" (UVa), y supone el punto de partida del Proyecto Los nuevos consumidores mediáticos: Millennials versus Generación Z (Cod. OCENDI08/1921) que está financiado por la Universidad de Valladolid y Panoramaaudiovisual.com para el período 2018-2021.

${ }^{2}$ En nuestra investigación dejamos al margen los programas deportivos que, aunque son muy seguidos por los jóvenes de todas las edades, no constituyen objeto de este estudio.

\section{Referencias}

AIMC (2019). Marco General del los Medios en España. Recuperado de http://bit.ly/2IMR5Xh

Alonso, N. (2018). Operación Triunfo y sus estrategias transmedia para recuperar al público joven. Recuperado de http://bit.ly/2mainHf

Baladrón, J. y Losada, J. (2012). Audiencias juveniles y los líderes de la telerrealidad. Revista de Estudios de Juventud, 96, pp. 51-69.

Barlovento Comunicación (2019). Análisis televisivo 2018. Recuperado de http://bit.ly/2IR91jm

Cáceres M. D. (2002). Operación Triunfo o el restablecimiento del orden social. Zer, 13. Recuperado de http://bit.ly/2kHzfVn

Carrasco, Á. (2010). Teleseries: géneros y formatos. Miguel Hernández Communication Journal, 1. Elche (Alicante): Universidad Miguel Hernández, pp. 174-200. Recuperado de http://bit.ly/2IR96Uc

El Confidencial (11/04/2017). "El 72\% de los jóvenes ve más YouTube que la televisión". El Confidencial. Recuperado de http://bit.ly/2m5JD9N

Estupiñán, O. J. (2010). La narrativa de los realities show en España: representaciones de la hiperrealidad y la hiperficcionalidad. Tesis doctoral defendida en el Departamento de Comunicación Audiovisual y Publicidad II. Universidad Complutense Madrid.

García, J. A. (2007). El infoentretenimiento en los informativos líderes de audiencia en la Unión Europea. Anàlisi, 35, pp. 47-63. Recuperado de http://bit.ly/2m52wcW

García, A.; Tur-Viñés, V. y Pastor, Y. (2018). Consumo mediático de adolescentes y jóvenes. Noticias, contenidos audiovisuales y medición de audiencias. Icono 14, Vol. 16 (1), pp. 22-46. Doi: 10.7195/ri14.v16i1.1101

Gómez , L. y López, N. (2015). Del éxito en televisión a la participación en las redes sociales. El Príncipe y Galerías Velvet en Facebook. Doxa Comunicación, 20, pp. 137-160. 
Grossmann, I. y Varnum, M. (2015). Social Structure, Infectious Diseases, Disasters, Secularism, and Cultural Change in America. Psychological Science, 26 (3), pp. 311324. University of Virginia: SAGE. Doi: 10.1177/0956797614563765. Recuperado de https://bit.ly/2mcY781

Hidalgo M. (2018). Pasado, presente y futuro del dating show en España: una panorámica del subgénero de telerrealidad. Estudios sobre el Mensaje Periodístico, 24 (1), pp. 623641. Doi: https://doi.org/10.5209/ESMP.59970 Recuperado de https://bit.ly/2xEdLeE

Horovitz, B. (4 de mayo de 2012). "After Gen X, Millennials, what should next generation be?". USA Today. Recuperado de http://bit.ly/2kvykHO

Imbert, G. (2005). De lo grotesco como contaminación de los géneros en los nuevos formatos televisivos. Revista deSignis, 7-8, pp. 159-170. Barcelona: Gedisa.

Lasexta.com (2018). La Voz, líder indiscutible del share social con un crecimiento del $75 \%$ en redes sociales la primera semana. Recuperado de http://bit.ly/2mdOaHz

León, B. (coord.) (2009). Telerrealidad. El mundo tras el cristal. Sevilla: Comunicación Social ediciones y publicaciones.

López , N. y Gómez, L. (2014). Nuevos hábitos de los jóvenes españoles y tendencias de futuro en el consumo de radio y televisión. Historia y Comunicación Social, Vol. 19, pp. 327340 .

López , N.; Medina de la Viña, E. y González, P. (2013). Los jóvenes españoles demandan una televisión con más ficción y entretenimiento. Ámbitos, 22, pp. 191-200. Sevilla: Universidad de Sevilla. Recuperado de: https://bit.ly/2m547PY

López, N.; González, P. y Medina de la Viña, E. (2011). Jóvenes y televisión 2010: un cambio de hábitos. Zer, vol. 16, nº 30, pp. 97-113. Recuperado de http://bit.ly/2kcHulR

Mercè, O. (2012). Fama y éxito profesional en «Operación Triunfo» y «Fama ja bailar!». Comunicar, 39 (vol. XX), pp. 185-192. Huelva: Grupo Comunicar. Recuperado de: http://bit.ly/2IR9GBm

Molina, B. (8 de noviembre de 2018). "GH VIP 6: la audiencia come de su mano (y estos datos lo demuestran)". El Confidencial. Recuperado de http://bit.ly/2kHzEqR

Pérez, L. (10/12/2018). "OT saca pecho de sus audiencias digitales, pero 'no sabemos qué pasa con el techo del $16 \%$ de share'". Vertele. Recuperado de: http://bit.ly/2m5JYJB

Prado, E. y Delgado, M. (2010). La televisión generalista en la era digital tendencias internacionales de programación. Telos, 84, pp. 52-64. Madrid: Fundación Telefónica.

Quintas, N. y González, A. (2014). Audiencias activas: Participación de la audiencia social en la televisión. Revista Comunicar, 43 (v. XXII), pp. 83-90. Huelva: Grupo Comunicar. 
ReasonWhy (13 de julio de 2017). Redacción. “¿Qué diferencias existen entre los Millennials y los Centennials?". Recuperado de http://bit.ly/2IMTqS3

Reinares, P. (2010). Jóvenes y televisión generalista en España: ¿Es Internet responsable de una audiencia perdida? Revista Estudios de Juventud, pp. 63-75.

Saló, G. (2003). ¿Qué es eso del formato? Barcelona: Gedisa (ACTV, Madrid).

Séntisis Analytics (2016). Gran Hermano. El reality con mayor conversación en redes sociales. Recuperado de http://bit.ly/2kaKci0

Strauss, W. y Neil, H. (2000). Millennials Rising: The Next Great Generation. New York: Vintage Original.

Terán, B. (2018). Las redes sociales: la otra arma de Telecinco para multiplicar las audiencias de Supervivientes. Recuperado de http://bit.ly/2IMTh0X

Terribas, M. y Puig, C. (2001). La teatralización de la esfera privada y la hibridación de los géneros televisivos. El caso Big Brother. Formats: revista de comunicació audiovisual. Recuperado de http://bit.ly/2mcX341 